http://dx.doi.org/10.30681/23588403v14i0106

\title{
A RENÚNCIA DA CAMÉLIA: O ACORDO ENTRE CORTESÃ E BURGUESIA
}

\author{
Beatriz Souza FERREIRA (IFSP) ${ }^{1}$
}

Data de recebimento: 06/05/2020

Data de aceite: $23 / 06 / 2020$

\begin{abstract}
Resumo: O presente trabalho tem por objetivo apresentar uma análise da obra teatral $A$ dama das camélias apontando para elementos do texto que indicam um acordo entre a personagem central da obra, Marguerite Gautier, a cortesã, e a família do seu amado Armand Duval, representante da burguesia. Será feita uma breve ilustração de dados biográficos do autor e de aspectos históricos do contexto da encenação e recepção da obra, para uma melhor compreensão da mensagem do romance. Entendemos aqui, baseados na leitura de Hobsbawm (1977) que o relacionamento dos dois jamais poderia se dar naquela organização social vigente, sustentando com as ideias propostas por Roland Barthes (2009), que a renúncia ao amor foi um acordo entre a cortesã e a burguesia emergente.
\end{abstract}

Palavras-chave: Acordo. Burguesia. Cortesã.

\begin{abstract}
The present work aims to present an analysis of the theatrical work The Lady of the Camellias, pointing to elements of the text that indicate an agreement between the central character of the work, Marguerite Gautier, the courtesan, and the family of her beloved Armand Duval, representative of the bourgeoisie. A brief illustration of the author's biographical data and historical aspects of the context of the staging and reception of the work will be made for a better understanding of the novel's message. We understand here, based on Hobsbawm's (1977) reading, that the relationship between the two could never take place in that prevailing social organization, sustaining with the ideas proposed by Roland Barthes (2009), that the renunciation of love was an agreement between the courtesan and the emerging bourgeoisie.
\end{abstract}

Keywords: Agreement. Bourgeoisie. Courtesan.

\section{Introdução}

O amor trágico é um mito que sustenta muitas obras e especialmente os romances da escola romântica do final do século XVIII até boa parte do século XIX. Amores impossíveis que exigem sacrifícios dos seus amantes, que auferem aos seus heróis e mocinhas qualidades muito nobres e inverossímeis, foram temas bastante produtivos na literatura e que até hoje influenciam diversos autores e artistas.

Também o ambiente cortês foi muito produtivo na literatura, desde a novela de cavalaria até o romance mais moderno, como os romances realistas do final do século XIX. Dentre as

\footnotetext{
${ }^{1}$ Graduanda em Letras pelo Instituto Federal de Educação, Ciência e Tecnologia de São Paulo, São Paulo, Brasil.E-
} mail: beatrizszf@gmail.com. 
figuras palacianas, a cortesã embalou enredos de muitas obras da escola romântica e fortalecia a ideia de amor impossível entre distintas classes sociais. A causa da impossibilidade desse amor é de ordem socioeconômica, já que a sociedade não toleraria jamais o casamento, a união entre um nobre, um burguês, ainda que emergente, com uma figura de classe social mais baixa e com quem a união não traria nenhum benefício social ou financeiro.

A Dama das Camélias, escrito por Alexandre Dumas Filho, em meados do século XIX, e que foi pelo próprio autor adaptado para o teatro, retrata fielmente a premissa de amor proibido por questões sociais. A peça foi bastante divulgada, chegou a ser encenada no Brasil, onde recebeu críticas positivas de ninguém menos que Machado de Assis, como revela Rondinelli (2013):

\footnotetext{
Machado de Assis também integra o rol de críticos teatrais que se dedicaram à avaliação de $A$ Dama das Camélias. Em seus artigos, na coluna teatral de $O$ Espelho, demonstrou simpatia para com o Teatro Ginásio Dramático e louvou a capacidade artística da atriz Gabriela da Cunha. Foi essa a posição que Machado de Assis adotou em sua crítica ao drama A Dama das Camélias, publicada em 8 de janeiro de 1860, quando a peça já estava em cartaz havia quatro anos no palco do Teatro Ginásio Dramático. Machado de Assis afirmou que, quando a obra surgiu, muitos não quiseram aceitar a ideia da reabilitação da "mulher perdida" pelo amor, a exemplo do dramaturgo Émile Augier, cuja peça $O$ Casamento de Olímpia seria um protesto contra as ideias de Dumas Filho. No entanto, o crítico defendeu o autor de A Dama das Camélias, pois Marguerite Gautier, assim como Maria Madalena e Eva, mostrava arrependimento, e isso seria moralmente positivo, já que expressava a ideia de salvação de uma alma que se perdia. (RONDINELLI, 2013).
}

Dada sua relevância para os discursos artísticos, sua importância para compreender o período histórico em que foi criada, o presente trabalho constitui uma análise de elementos da peça A Dama das Camélias. Assim, serão explicitados elementos pertinentes ao seu texto, com enfoque sobre a personagem Marguerite Gautier, elencando os principais pontos da peça que interessam nesta análise, finalizando com uma crítica sobre as relações sociais que estão implicadas na renúncia da personagem ao seu grande amor, através da teoria de análise literária e de pressupostos críticos de autores como Carpeaux, Roubine, Roland Barthes, e apontamentos históricos de Eric Hobsbawn.

\section{2. $O$ autor e o teatro francês}

Alexandre Dumas Filho nasceu em Paris, em junho de 1824, filho do escritor Alexandre Dumas (autor francês de obras como $O$ conde de Monte Cristo, Os três mosqueteiros) e de uma 
lavadeira, Catherine Labay. Em sua infância, o jovem Dumas foi educado pela mãe nos arredores de Paris, e só conheceu o pai em 1831. Após ter conhecido o escritor, foi inscrito por ele em um colégio interno, e também por meio dele foi introduzido na sociedade parisiense do século XIX. Aos poucos o jovem escritor foi conquistando seu espaço e deixando de depender da fama paterna, começando sua carreira publicando poemas em jornais.

Em meio a esses ambientes ricos e elegantes conheceu, em 1842, aos dezoito anos, uma jovem de vinte anos. Era uma famosa cortesã, Marie Duplessis, que tinha clientes como o compositor Franz Liszt e de quem o jovem Alexandre tornou-se amante. Há especulações de que Duplessis seria a inspiração para sua obra A Dama das Camélias. Em 1851, o livro foi transformado em peça de teatro que, tendo sido considerada imoral para a época, só foi representada um ano depois.

No teatro, a comunicação assume formas diferentes pelo modo como chega ao público, o não poder voltar nas falas do personagem, por exemplo, o fato de que ali, na encenação, não estará presente apenas a visão do autor, mas aquilo que o diretor compreendeu da peça, a forma como ele optou por representar uma obra, entre outros aspectos diferenciais. Além disso, os atores ajudam a transmitir ao público aquilo que o texto quer levar. Então, através da representação teatral o público tem acesso a três vozes, a princípio: a do autor, a do diretor e a dos personagens.

Além dos atores, diretor, o teatro também tem os seus espectadores. Na peça A Dama das Camélias, pela época em que foi escrita e representada, entende-se que o seu público não poderia ser outro que não a burguesia, membros da nobreza europeia, que eram quem financiavam as expressões artísticas do período, e que poderia pagar pelo acesso às manifestações culturais. A obra aqui trabalhada discursa em favor do moralismo burguês, o que contribuiu, provavelmente, para seu sucesso e aclamação, além de releituras, como o filme dirigido por Baz Luhrmman de 2001, Moulin Rouge: o amor em vermelho, mantendo-se o romance de Dumas Filho uma inspiração ainda hoje.

A época na qual Dumas Filho ascendia no cenário artístico foi um período em que representações de obras de outros autores como Honoré de Balzac, seu próprio pai e outros, também eram encenadas nos teatros parisienses. Destarte, as peças do autor foram ganhando destaque, e ele conheceu o auge quando foram apresentadas ao público pelo Théâtre $D u$ Gymnase, criado em 1860. Dumas Filho então moralista defensor da burguesia, alcançou êxito com suas obras, apesar de alguns aspectos polêmicos que elas continham para a época.

\section{A composição da obra}


A tarefa de narrar é, no teatro, função da personagem, dos atores. Diferentemente de uma narrativa convencional, em que um narrador dá sua versão da história, seja ele um personagem, onisciente, protagonista, no teatro é a personagem quem vai contar a história, e o espectador terá que se atentar àquilo que no romance vem escrito, mas no palco é dramatizado: o olhar, as expressões gestuais, faciais, entre outros elementos. Além de compreender as vozes sem as quais o teatro não é possível, o espectador tem também a tarefa de compreender o discurso de uma peça teatral considerando desde o texto escrito, até as menores ações e reações dos atores em cena.

A peça é representada com as seguintes personagens, na tradução brasileira: Armando Duval, seu pai Jorge Duval, Margarida Gautier, Gastão Rieux, Saint-Gaudens, Gustavo, Conde de Giray, Arthur de Varville, o Médico, Arthur, o Mensageiro, Nichette, Prudência, Nanine, Olímpia, Anais mais os empregados e convivas.

As ações da obra ocorrem onde vive Marguerite, em uma casa de campo e na casa de Olímpia. A peça é dividida em cinco atos. Inicia-se com um diálogo entre as personagens Varville e Nanine sobre a afeição que o conde tem por Marguerite em virtude da sua semelhança com a filha falecida. Na adaptação teatral, essa relação com o conde ficou bem nítida por meio da fala de Nanine, que adverte Varville por seus comentários. Outra característica bem marcante na obra é o caráter caprichoso da cortesã, conforme é possível ver na seguinte passagem:

\footnotetext{
MARGARIDA- Que apelido me deram?

VARVILLE- A dama das camélias.

MARGARIDA- Por que?

VARVILLE- Porque são as únicas flores que costuma usar.

MARGARIDA- O que quer dizer que são as únicas flores que me agradam, e que é inútil me mandarem outras. Se pensou que lhe ia abrir uma exceção, enganou-se, Varville. O perfume me enerva. (DUMAS FILHO, 1965, p. 10).
}

A peça foi adaptada devido a questões morais, foi representada em 1852, no Theatro de Vaudeville, apontando assim, para sequências de apresentações ainda no século XIX, no século XX no Brasil, e seguindo até a atualidade com releituras. A sociedade daquele período não aceitaria de bom grado o envolvimento de um jovem em ascensão, honesto, de família ilibada, relacionando-se com uma cortesã, e no teatro, como nas demais narrativas, a verossimilhança é condição imprescindível para aceitação, em conformidade com o exposto por Roubine:

O decoro é indissociável da busca da verossimilhança. Mas não se confunde com ela. Define um sistema de coerções que derivam não da economia interna da fábula ou dos dados comprovados pela Lenda ou pela História, mas de uma vulgata da qual o espectador seria o detentor. O dramaturgo deve portanto evitar qualquer descompasso entre essa vulgata e sua peça. Isso significa que, nesse sistema, a singularidade histórica não tem lugar. Seja um rei: pouco 
importa que pertença à Lenda (Pirro, Teseu, etc), à História (Augusto, Nero, Tito etc). Pouco importa que seja grego, romano ou otomano. Deve em primeiro lugar adequar-se à imagem que o público faz da realeza (ou talvez à imagem que se pretende que ele faça). (ROUBINE, 2003, p. 52).

Assim, para ter sua obra aceita pelo público, seu nome reconhecido, para ter sucesso nas bilheterias, Dumas Filho não poderia conceber uma personagem que não fosse aprovada pelos seus espectadores. E se, tendo decidido ousadamente escrever um romance sobre um jovem emergente e uma cortesã, caberia a essa personagem possuir virtudes que passassem pelo crivo moralista burguês.

O jovem e promissor advogado Armando Duval apaixona-se por uma cortesã, Margarida Gautier. Ele tem uma família formada pelo pai e pela irmã, a qual está prestes a fazer um bom casamento, razão que leva o pai do jovem a intrometer-se na relação do filho com a prostituta. Margarida, que era conhecida por estar sempre com um buquê de camélias quando ia ao teatro, era sustentada pelo seu trabalho, pelos seus amantes e pelo conde que via nela a imagem de sua filha, começa a mudar o estilo de vida ao se ver amada e enamorada pelo jovem advogado.

Contudo, conflitos que envolvem a relação dos amantes acabam por enfraquecer o relacionamento: Margarida tem um problema de saúde e Armand não tem dinheiro suficiente para manter a si e a amada, e com o casamento da irmã com uma figura importante da sociedade, o pai do jovem convence a cortesã a se afastar do filho, já que se ela o ama, argumenta o pai, ela deve permitir que o nome da família seja imaculado, pois continuar com Armando seria sujar o nome da família, provocando o afastamento do noivo da irmã.

Percebe-se que todo o enredo é trabalhado em torno de relações financeiras. O jovem, um rapaz em ascensão social, cuja irmã precisa fazer um bom casamento, matrimônio que atende a interesses comerciais e financeiros do pai; o amor dos protagonistas é encontra já um obstáculo no início porque ele não tem dinheiro para manter a amante, que, por sua vez, precisa do dinheiro, não para cobrir seus gastos, dos quais ela se dispôs a renunciar por amor, mas para cuidar da saúde, e isso não é possível ao lado de Armando.

É quando então, para destruir de vez qualquer possibilidade desse amor, no qual o senhor Duval até acredita, mas não corrobora, faz a proposta:

DUVAL - A senhora é mais generosa que as outras mulheres, por isso é como um pai que eu the falo, como um pai que lhe vem pedir a felicidade de seus dois filhos.

MARGARIDA- De seus dois filhos?

DUVAL - É, Margarida, de meus dois filhos. Ouça o que me trouxe à sua 
presença. Tenho uma filha, bonita, moça, pura como um anjo. Gosta de um rapaz e fez desse amor o sonho de sua vida. Creio que também tem direito ao amor. [...] Pois bem! Minha filha vai se casar com um homem direito, entrar numa família honrada, que espera da nossa a mesma honradez. Mas a sociedade tem exigências, Margarida, principalmente a sociedade de província; e se seu amor por Armando pode purificá-la aos olhos dele e também aos meus, não a purifica aos olhos de uma sociedade que só há de ver na senhora o seu passado e que vai lhe fechar as portas, sem piedade. A família de meu futuro genro soube da vida de Armando, e me declarou que retiraria a palavra dada se ele prosseguisse na vida que leva... Está em suas mãos o destino de uma moça que não lhe fez nenhum mal. Em nome de seu amor, Margarida, conceda-me a felicidade de minha filha.

MARGARIDA — Quanta bondade em suas palavras... Diante do seu pedido o que posso fazer? Eu o compreendo, sei que o senhor tem razão. Vou sair de Paris, vou me afastar de Armando por algum tempo. Vai ser doloroso, mas faço esse sacrifício, para que o senhor nada tenha a me censurar... Aliás, a alegria da volta me fará esquecer a tristeza da separação. O senhor dará licença para ele me escrever de vez em quando e depois do casamento...

DUVAL - Obrigado, Margarida, obrigado pela sua compreensão... mas o que estou pedindo é outra coisa.

MARGARIDA - Outra coisa? Mas o que mais podia me pedir, meu Deus? DUVAL - Ouça, Margarida; vou lhe falar com franqueza: uma separação provisória, não basta.

Margarida — Então quer que eu deixe Armando para sempre?

DUVAL-É preciso!

Margarida então, abandona o amado. Ele sem saber do acordo dela com o pai, afasta-se e quando tudo se esclarece, já é muito tarde para o romance dos dois. A nobreza de espírito da dama das camélias é de enternecer o coração dos mais românticos defensores da moral. Assim, em alguns críticos, a cortesã chega a ser vista como representante de Maria Madalena, a mulher regenerada. Mas aqui apresenta-se uma leitura diferente da personagem de Dumas Filho. Serão elencadas características que interessam à elaboração de um retrato da situação marginal da fictícia cortesã na Paris no século XIX e uma leitura possível da atitude de Margarida sob a ótica de Dumas Filho e também do que a sociedade da época permitiria.

\subsection{A cortesã sob a ótica de Dumas Filho}

A prostituição é uma temática muito abordada na literatura. Foi tema de romances de 
Balzac, de romances mais modernos, como Crime e Castigo, de Dostoiévski, Nana, de Zola, entre outros. E, em se tratando de um romance cujo cenário é a Paris do século XIX, cujas noites eram muito famosas e imbuídas de glamour despertando curiosidade e lendas, o romance com uma personagem cortesã não deveria causar estranheza. Apenas há uma mudança com relação ao retrato da figura na obra.

Apesar da vida fora dos padrões sociais, Marguerite é nobre, boa, estimada. Mesmo considerando os amantes que teve, a sua relação com o duque mais velho era uma relação paternal. Vendo nela a filha perdida, ele faz por ela o que pode e acaba vivendo essa sensação de perda duplamente, pois Marguerite, a substituta da filha, também é perdida para sempre.

A história da prostituta arrependida é uma história já bastante conhecida, que remete à história bíblica, à Maria Madalena. Mas Marguerite não é Maria Madalena. É uma infeliz cortesã da Paris do século XIX, que teve a infeliz "ideia” de se apaixonar, e que, devido à sua situação social, não pode viver esse amor.

A obra do escritor francês leva a uma interpretação de defesa de valores familiares: "Dumas Filho defendeu a liberdade erótica dos filhos contra as convenções rigorosas da família francesa, das quais a 'prostituta virtuosa' se torna a vítima”. (CARPEAUX, 2008, p. 1902). Assim, para o crítico, diferentemente dos seus antecessores, que queriam mostrar à sociedade o perigo da mulher mundana, a problemática das relações eróticas, em Dumas Filho, a cortesã torna-se uma figura comedida, capaz de renúncia e sacrifício, digna da confiança e respeito de um honrado pai de família, sendo ela uma figura "com mais espírito e talvez um pouco mais de coração que as outras", capaz de sentir um amor sincero e renunciar à sua felicidade para garantir a felicidade dos inocentes.

\section{A renúncia da camélia: o acordo entre cortesã e burguesia}

Marguerite é jovem, experiente, conhecedora dos mistérios da noite e das relações fugazes que permeiam a sociedade parisiense. Teve seus amantes, é sustentada por eles e é muito caprichosa. Ao se apaixonar, passa por uma transformação, deixando de ser apenas a mulher mimada e fútil, e passa a mostrar que conhece sua situação.

Mais do que uma cortesã em busca de dinheiro e diversão, ela é capaz de sacrifícios por amor. Quando começa a regeneração em seu espírito por meio do mais nobre dos sentimentos, o Senhor Duval surge para recordá-la de sua real situação, de qual papel ela ocupa naquela sociedade.

A história amorosa do filho é de grande inconveniência para a sua família. Defendendo 
seus valores burgueses, da família tradicional com um nome a zelar, o pai do advogado pede que Marguerite abandone o filho para salvaguardar seu nome e sua família, não exatamente pelas questões morais, mas pelas relações financeiras que estavam em jogo, em conformidade com Hobsbawm:

[...] A família não era meramente a unidade social básica da sociedade burguesa, mas também a unidade básica do sistema de propriedade e das empresas de comércio, ligadas com outras unidades similares através de um sistema de trocas mulher-mais-propriedade (o dote do casamento) em que as mulheres deveriam, por estrita convenção derivada de uma tradição pré-burguesa, ser virgines inlactae. Qualquer coisa que enfraquecesse esta unidade familiar era inadmissível, e nada a enfraquecia mais do que a paixão física descontrolada, que introduzia herdeiros e noivas "inadequados" (isto é, economicamente indesejáveis), separava maridos de mulheres e desperdiçava recursos comuns. (HOBSBAWM, 1977, p. 243).

Essa passagem ilustra quais as complexidades sociais envolviam o romance do casal protagonista, corroborando que o impedimento da relação não era de cunho moral universal, mas de uma máscara de moral burguesa, cujo único interesse real eram as questões financeiras que estavam em pauta. Marguerite, uma cortesã, vivida, apaixonada mas caprichosa, acata ao pedido do pai do amado, pedindo em troca apenas que ele reconheça que ela ama o filho. Duval então reconhece, num acordo tácito, que o amor é sincero e então ela consente em deixar Armand. Sobre isso, Roland Barthes afirma:

Inicialmente, ela fica sensibilizada por se sentir reconhecida por Armand, e a paixão foi para ela, em seguida, apenas a solicitação permanente desse reconhecimento, razão pela qual o sacrifício que ela concede ao Sr. Duval, renunciando a Armand, não é de modo algum moral (apesar da fraseologia), mas sim existencial; não é mais do que a consequência lógica do postulado de reconhecimento, um meio superior (muito superior ao amor) de fazer com que o mundo dos "senhores" a reconheça. E, se Marguerite esconde o seu sacrifício sob a máscara do cinismo, isso só acontece no momento que o argumento se transforma de fato em Literatura: o olhar agradecido dos burgueses é delegado aqui ao leitor, que, por sua vez, reconhece Marguerite por meio do próprio equívoco do amante. (BARTHES, 2009, p. 181).

Destarte, para Barthes a renúncia de Marguerite a Armand não é feita por moral, nem mesmo ocorre por amor, mas para que ela tenha o reconhecimento da sociedade burguesa. O que separa os dois amantes é o capital mascarado de convenção social. Nesse contexto, não haveria problema se Armand quisesse se divertir com a cortesã, algo muito recorrente no romance, já que Marguerite estava sempre em contato com senhores da alta sociedade. Ele poderia se divertir com a prostituta como esses senhores faziam, mas unir-se a ela, passar a ter com a cortesã um compromisso social e financeiro, sem ter nenhuma recompensa econômica de volta, era completamente inconcebível para os padrões daquela sociedade.

E, segundo Barthes, esse reconhecimento cabe ao leitor. No caso da peça de teatro, esse 
trabalho de reconhecimento é passado ao espectador, que vai assistir à peça e se emociona com a renúncia de uma moça regenerada pelo sublime, mas que precisa sair de cena para que ocorra a emergência da burguesia.

Para simbolicamente ter um pacto com essa camada social, Gautier afasta-se do amado, o pai agradece o sacrifício e reconhece a sinceridade da mulher, assim como o público da peça. Negócios são comuns à burguesia, também o são para as cortesãs, cientes de seu papel social marginalizado, porém, aquilo que pode ser visto como um grande sacrifício, ganha assim, uma configuração de acordo compensatório, ainda que financeiramente ela nada esteja ganhando.

É possível também compreender que o acordo com o pai de Armand em busca de reconhecimento não é o único negócio acertado entre Marguerite e a burguesia, ela está o tempo todo em constante negociação, em busca de ascensão, de reconhecimento. Ora com sua relação com Prudence, que a explora impiedosamente, ora com seus amantes, a quem finge não reconhecer quando eles se encontram na vida social que necessita de uma postura idônea, que não permite que se trate com cortesãs, ela então se comporta serenamente, ratificando o ponto de vista de um acordo implícito entre cortesã e burguesia.

\section{Considerações finais}

Nesse trabalho foram apresentados elementos da versão adaptada para o teatro do romance A Dama das Camélias, de Alexandre Dumas Filho. Foram evidenciados aspectos relacionados a fatores históricos no qual se deu a elaboração e representação da peça, além de levantamento de aspectos sociais constitutivos da obra.

Para desenvolver a ideia central de acordo entre a cortesã e a burguesia foram evidenciados fundamentos teóricos fomentados por Roubine, Hobsbawn e Barthes. A consulta permitiu elucidar aspectos de ordem econômica que permeia a relação proibida entre cortesã e um jovem de família burguesa.

Por fim, ficou evidenciado através dos pressupostos elencados que o mote para o desenvolvimento da obra foi a distância social e econômica entre os protagonistas, realçado sobretudo pela necessidade de Marguerite de buscar um reconhecimento da burguesia. Reconhecimento pelas suas constantes renúncias, e, sobretudo pela maior delas, a renúncia ao seu amor.

\section{Referências}

BARTHES, Roland. Mitologias. Trad. Rita Buongermino. Rio de Janeiro: DIFEL, 2009. 
CARPEAUX, Otto M. História da literatura ocidental. Vol. 3. Brasília, 2008. Disponível em:

<http://www2.senado.leg.br/bdsf/bitstream/handle/id/528992/000826279_Historia_Literatura _Ocidental_vol.III.pdf?sequence=3>. Acesso em julho de 2018.

DUMAS FILHO, Alexandre. A Dama das Camélias. Prefácio de Alfredo Mesquita. Rio de Janeiro: Paz e Terra, 1997.

DUMAS FILHO, Alexandre. A Dama das Camélias. Trad. Gilda de Mello e Souza. São Paulo: Brasiliense, 1965.

HOBSBAWM, Eric. A era do capital. Trad. Luciano Costa Neto. Rio de Janeiro: Paz e Terra, 1977.

RONDINELLI, Bruna Grasiela da Silva. A Dama das Camélias desembarca no Rio de Janeiro: encenações e recepção crítica (1856-1860). Miscelânea, Assis, v. 14, p.101-121, juldez. 2013

ROUBINE, Jean- Jacques. Introdução às grandes teorias do teatro. Trad. André Telles. Rio de Janeiro: Jorge Zahar Ed., 2003. 